\title{
Effect of Internalized Stigma on Self-Esteem and Loneliness among Mentally Ill Patients
}

\author{
Lobna Atya Elwan Ali ${ }^{1}$, Amal Ibrahim Sabra ${ }^{2}$, Amal Ibrahim Sabra ${ }^{3}$ \\ ${ }^{1}$ Psychiatric and Mental health nursing, ${ }^{2}$ Assistant Professor Psychiatric and Mental health \\ nursing Department, Faculty of nursing, Tanta University, ${ }^{3}$ Lecturer of Psychiatric and Mental \\ health nursing Department, Faculty of nursing, Benha University
}

\begin{abstract}
Recent research studies have shown that, stigma against people with mental illness is universal. Stigmatized individuals have been found to face a variety of social and emotional consequences including social withdrawal, lowered self-esteem and increased levels of negative affect. This study was a descriptive correlational. Therefore, the purpose of this study was to identify the relationship between internalized stigma, self-esteem and loneliness among mentally ill patients. The study was conducted in inpatient ward of Benha Mental Health Hospital. Four instruments were used for collecting the data, socio-demographic and clinical data sheet, Internalized Stigma of Mental Illness Scale, Rosenberg self-esteem scale and UCLA loneliness scale. A convenient sample of 100 psychiatric patients was recruited in this study. The main results revealed that, there were negative correlation between internalizing stigma and selfesteem and show positive correlation with loneliness among studied subjects. The study recommended that there is an urgent need for developing strategies to fight internalized stigma associated with mental illness.
\end{abstract}

Keywords: mental illness - Internalized stigma- self-esteem- loneliness.

\section{Introduction}

Individuals who are mentally ill are often the targets of bias and stigma and thus susceptible to negative attitudes. As a result, the social and psychological consequences are usually serious and pervasive (Cheon \& Chiao, 2012). In some studies, stigma toward mental illness has been linked to poor psychosocial outcomes such as low selfesteem, high rates of depressive symptoms, poor subjective quality of life and loneliness (Ow \& Lee, 2015)\&(yen et al., 2015).

Internalized stigma can create enormous pain for persons with mental illness and may undermine vocational functioning. Additionally it can pervade their lives in many different ways; it diminishes selfesteem and robs people of social opportunities. This can include being denied opportunities such as employment or accommodation because of their illness (Yanos et al., 2014).
In fact, stigma is one of the remaining greatest obstacles to the treatment of mental illness. It has been associated with lower self-esteem, depression, feeling misunderstood and ashamed, poor medication adherence, fewer successful social interactions, reduced help seeking, worse recovery, lower quality of life, fewer job opportunities, inadequate health coverage, and fewer leased apartments (Guyll et al., 2013).

One of the most tragic consequences of internalized stigma of mental illness is the possibility that it can cause loss of selfesteem specifically, that the stigma of mental illness leads a substantial proportion of people who develop such illnesses to conclude that they are failures or that they have little to be proud of (Farrelly et al., 2015).

When anyone, mentally ill or not, does not have enough social contact, it affects them mentally and even physically. 
Loneliness creates stress, taking a toll on health (yuksel et al., 2013). Other things affected can be the ability to learn and memory function. High blood pressure is also seen. It can be the trigger of depression and alcoholism. Imagine the consequences, then, if you are already depressed or have other mental illnesses? Loneliness can make you worse. Loneliness and loss of self-worth lead many mentally ill to believe that they are useless, and so they live with a sense of hopelessness and low self-esteem (Oexle et al., 2018).

For this reason, this study was conducted to identify the relationship between internalized stigma, self-esteem and loneliness among mentally ill patients.

\section{Purpose of the study:}

The purpose of this study is to identify the relationship between internalized stigma, self-esteem and loneliness among mentally ill patients.

\section{Research question:}

Is there a relation between internalized stigma, self-esteem and loneliness?

\section{Methods:}

\section{Research design:-}

Descriptive correlational design was utilized in this study to achieve the purpose of the study.

\section{Study setting:-}

The study was conducted in psychiatric inpatient ward at psychiatric mental health hospital in Benha city. The hospital is affiliated to General Secretariat of Mental Health. The hospital is divided in three building with capacity of 295 beds and total number of patients 175 patients.

\section{Sampling:-}

A convenient sample of 100 of psychiatric inpatients was recruited at inpatient psychiatric ward who met the following:-

\section{Inclusion criteria:}

A. The patient age 18:65 years.

B. The patient had history of mental illness for more than one year.

C. Hospitalized twice or more.

\section{Exclusion criteria:}

Patients had the following criteria which itself may be source of stigma:-

A. Mentally retarded patients.

B. Physical disability (e.g. hearing or visual disability).

C. Addiction.

D. Neurological disorders (e.g. epilepsy).

\section{Instruments:-}

Four instruments were used for data collection of the study.

instrument one: Socio-characteristics and clinical characteristicsof the sample:-

It was developed by the researcher. It was concerned with the following:

A. Socio-characteristics data: It contained 7 items (age, sex, educational level, residence, occupation, marital status and income).

B. Clinical charcteristics: it consisted of 4 items (diagnosis, duration of illness, number of admissions to hospital, mode of current admission).

Instrument two: Internalized stigma of mental illness inventory (ISMI):

It was developed by Ritsher and Jennifer (2003). It aimed to measure self-stigma of mental illness among persons with mental illness. It consisted of 29 items, each statement was rated on the following 4 point anchored likert scale: $1=$ strongly disagree, $2=$ disagree, $3=$ agree, $4=$ =strongly agree. This scale was divided into 5 subscales: alienation, stereotype endorsement, perceived discrimination, social withdrawal, and stigma resistance. 
Subscale 1: The alienation subscale. It consisted of 6 items (1-6) included items such as "having a mental illness has spoiled my life" and "I feel out of place in the world because I have a mental illness".

Subscale 2: The stereotype endorsement subscale. It contained 7 items (7-13) measuring the degree to which respondents agree with common stereotypes about people with mental illness, such as "mentally ill people tend to be violent" and "I can't contribute anything to society because I have a mental illness".

Subscale 3: The discrimination experience subscale. It was composed of 5 items(14-18) intended to capture respondents' perception of the way that they currently tend to be treated by others, such as "people ignore me or take me less seriously just because I have a mental illness" and "people discriminates against me because I have a mental illness".

Subscale 4: The social withdrawal subscale. It was especially heavily influenced by focus group participants, and contained 6 items(19-24), such as "I don't talk about myself much because I don't want to burden others with my mental illness" and "I avoid getting close to people who don't have mental illness to avoid rejection".

Subscale 5: The stigma resistance subscale. It consisted of 5 items (24-29). It was intended to portray the experience of resisting or being unaffected by internalized stigma, such as "I can have a good, fulfilling life, despite my mental illness", and "I feel comfortable being seen in public with an obviously mentally ill person. The higher score, the higher the internalized stigma patients have.

Tool III: The Rosenberg Self-esteem scale (Rosenberg, 1965):-
The Rosenberg Self-esteem scale is most widely used self-esteem measure. It was developed by Rosenberg (1965). The scale consists of ten items in which five of them are positive $(1,2,4,6,7)$ and others are negative $(3,5,8,9,10)$. Each item was measured in four point likert-type from strongly agree to strongly disagree.

Scoring system: - to score the items, assign a value to each of ten items as follows: - For items 1, 2, 4, 6, 7 strongly agree $=3$ and strongly disagree $=0$. For items 3, 5, 8, 9, 10 (which are reversed in valence) strongly agree $=0$ and strongly disagree $=3$. The scale ranges from $0-30$ with 30 indicating the highest scale possible.

- Low self-esteem: 0-10

- Moderate self-esteem: 11-20

- High self-esteem: 21-30

Tool IV:-UCLA loneliness scale:-

The UCLA loneliness scale was developed by Russel (1980) to assess subjective feeling of loneliness as well as feeling of social isolation. This scale includes 20 likert-type questions on a four-point likert scale, these 20 item scale ask participants how frequently they agree with statements such as "I feel left out" "I am no longer close to any one" and "my social relationships are superficial". Agreement is measured on a four-point of likert scale ranging from $1=$ never and 4=often. Items 1-5-6-9-1015-16-19-20 are reverse score.

\section{Scoring System:}

- 15-20 People attaining this score-range are operating comfortably and experience an average level of loneliness.

- 21-30 People within this range struggle a little with social interactions, experiencing frequent loneliness.

- 31-40: Scores falling within this range would indicate a person experiencing severe loneliness. 


\section{Methods:}

\section{Pilot Study}

Before actual study a pilot study was conducted on $10 \%$ (10 patients) of psychiatric in order to test the clarity of the tools to see if it is clear and fulfilling their purpose. As well as to identify the obstacles and problems that may be encountered during data collection. It served also to estimate the approximate time required for interviewing the patients. After obtaining the result of pilot study, no modifications of tools were done then the final format was developed under the guidance of supervisors. Those patients were excluded later from the actual study.

\section{Ethical consideration}

All subjects were informed that participation in the study is voluntary. Anonymity and confidentiality of each participant will be respected and protected. Subjects were informed that the content of the tool will be used for research purpose only. Subjects had the right to refuse to participate in the study or withdrawal at any time. After full explanation of the aim of the study oral consents were taken before participation on the study

\section{Procedure:}

1- An official letter was submitted from the dean of the faculty of nursing to the administrator of Benha mental health hospital.

2- The researcher started data collection by introducing herself to the participant.

3- Brief description of the purpose of the study was given to each participant.

4- Data collected were done through interviewing with the patients in hospital in an individual basis. Each interview lasted for 20- 30 minutes, depending on the response of the patients. The process of data collection took three months from: July (2017) to September (2017).

\section{Statistical analysis}

The collected data was organized, tabulated, scored, and analyzed using the statistical package for social science (SPSS) version 20. Data was presented using descriptive statistics in the form of frequencies, and percentages and X2 was used for qualitative data correlation. Confidence spearman was used for correlation. Statistical significant level value was considered when $p$-value $<0.05$ and highly significant level value was considered when $\mathrm{p}$-value $<0.001$ while $\mathrm{p}$ value of $>0.05$ indicated no significant.

\section{Results:}

Table 1 shows distribution of the studied patients regarding their sociodemographic characteristics. this table illustrates that about $51 \%$ of the studied patients were female. Most of the studied subjects $30 \%$ had age from $45 \leq 55$ years. Regarding level of education, $44 \%$ of the studied patients read and write and only $1 \%$ had university education. On other side $38 \%$ were working. The table also revealed that $41 \%$ of them were married and $9 \%$ were widowed. Finally, more than half of the studied patients $(58 \%)$ were from rural and their income was enough for $31 \%$, didn't enough for $62 \%$ and only $7 \%$ can save from it.

Table (2) represents distribution of studied patients regarding their clinical characteristics it was illustrated that duration of illness of only $9 \%$ of the studied sample was one year while $36 \%$ of them were 3 years and $12 \%$ of the studied subjects admitted to psychiatric hospitals for 2-4 times while $45 \%$ of them were admitted more than 6 times. It can be noticed that $(56 \%)$ more than half of the studied subjects were involuntary admission. On the other side more than half of the studied subject's diagnosis was schizophrenia. 
Figure (1) describes the distribution of studied patients regarding levels of internalized stigma (ISMI). The results revealed that most of the studied patients $(38 \%, 36 \%)$ were suffering from severe and moderate levels of internalized stigma compared to only $13 \%$ of subjects suffered from mild and minimal stigma.

Figure (2) reveals distribution of studied patients regarding levels of the Rosenberg self-esteem scale. It showed that the majority of the studied patients had low self-esteem $(82 \%)$ while only $(8 \%)$ had high self-esteem.

Figure (3) shows that distribution of the studier subjects regarding levels of UCLA loneliness scale were $(44 \%, 36 \%)$ of the studied patients suffered from severe and moderate loneliness and only $20 \%$ didn't feel alone.
Table (5) illustrates correlation between internalized stigma (ISMI) and selfesteem among studied patients. It showed that there was highly negative statically correlation between internalized stigma and self-esteem. That means that patients who had more internalized stigma, become more likely to have low selfesteem.

Table (6) Correlation between internalized stigma of mental illness inventory (ISMI) and UCLA loneliness scale among studied patients is showed in this table. It was clear that there were highly positive significant correlation between internalized stigma and loneliness p-value was 0.000 . That means that patients who had more internalized stigma become more likely to have high loneliness score.

Table (1): distribution of the studied patients regarding their socio-demographic characteristics.

\begin{tabular}{|c|c|c|}
\hline \multirow{2}{*}{ Socio-demographic characteristics items } & \multicolumn{2}{|c|}{ Studied subjects $N=100$} \\
\hline & No & $\%$ \\
\hline \multicolumn{3}{|l|}{ Age } \\
\hline $18 \leq 25$ years & 8 & 8.0 \\
\hline $25 \leq 35$ years & 16 & 16.0 \\
\hline $35 \leq 45$ years & 25 & 25.0 \\
\hline $45 \leq 55$ years & 30 & 30.0 \\
\hline $55 \leq 65$ years & 21 & 21.0 \\
\hline \multicolumn{3}{|l|}{ Sex } \\
\hline Male & 49 & 49.0 \\
\hline Female & 51 & 51.0 \\
\hline \multicolumn{3}{|l|}{ Marital status } \\
\hline Single & 41 & 41.0 \\
\hline Married & 30 & 030.0 \\
\hline Separated & 8 & 8.0 \\
\hline Divorced & 12 & 12.0 \\
\hline Widowed & 9 & 9.0 \\
\hline \multicolumn{3}{|l|}{ Level of education } \\
\hline Illiterate & 31 & 31.0 \\
\hline Read and write & 44 & 44.0 \\
\hline Intermediate education & 24 & 24.0 \\
\hline University education & 1 & 1.0 \\
\hline \multicolumn{3}{|l|}{ Occupation } \\
\hline Working & 38 & 38.0 \\
\hline Not working & 62 & 62.0 \\
\hline \multicolumn{3}{|l|}{ Residence } \\
\hline Rural & 58 & 58.0 \\
\hline Urban & 42 & 42. \\
\hline \multicolumn{3}{|l|}{ Income } \\
\hline Enough & 31 & 31.0 \\
\hline Not enough & 62 & 62.0 \\
\hline Can save from it & 7 & 7.0 \\
\hline
\end{tabular}


Table (2): distribution of studied patients regarding their clinical characteristics

\begin{tabular}{|c|c|c|}
\hline \multirow[t]{2}{*}{ Clinical characteristics } & \multicolumn{2}{|c|}{ Studied subjects $\mathrm{N}=100$} \\
\hline & No & $\%$ \\
\hline \multicolumn{3}{|l|}{ Duration of illness } \\
\hline 1 year & 9 & 9.0 \\
\hline 2 years & 25 & 25.0 \\
\hline 3 years & 36 & 36.0 \\
\hline More than 4 years & 30 & 30.0 \\
\hline \multicolumn{3}{|c|}{ Number of admission to psychiatric hospitals } \\
\hline $2-3$ times & 12 & 12.0 \\
\hline $4-6$ times & 43 & 43.0 \\
\hline More than 6 times & 45 & 45.0 \\
\hline \multicolumn{3}{|c|}{ Mode of current admission } \\
\hline Voluntary & 44 & 44.0 \\
\hline Involuntary & 56 & 56.0 \\
\hline \multicolumn{3}{|l|}{ Diagnosis } \\
\hline Schizophrenia & 59 & 59.0 \\
\hline Depression & 10 & 10.0 \\
\hline Bipolar disorder & 31 & 31.0 \\
\hline
\end{tabular}

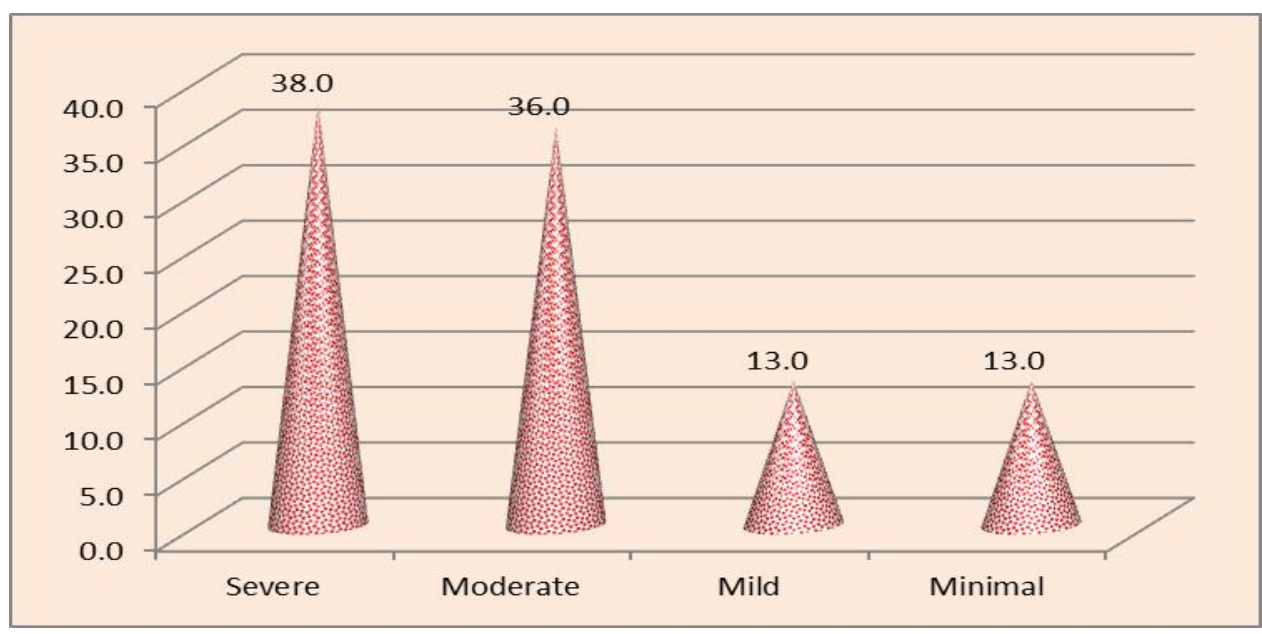

Figure (1): distribution of studied patients regarding levels of internalized stigma (ISMI).

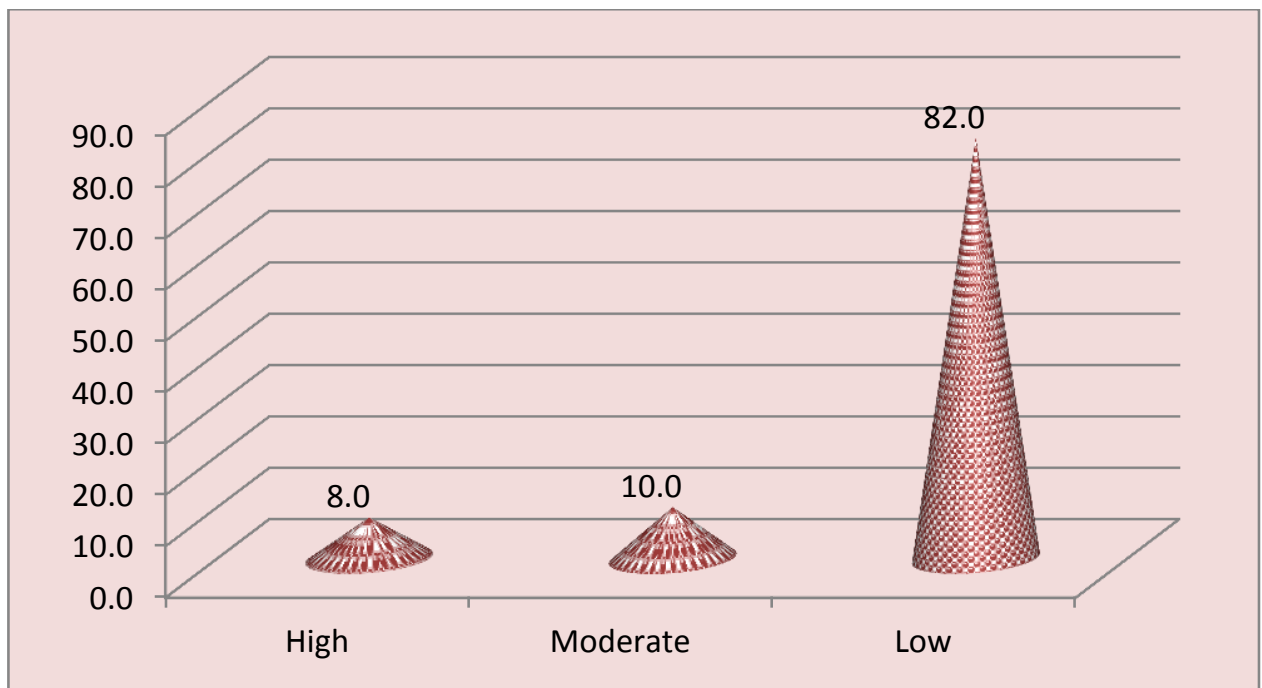

Figure (2) distribution of studied patients regarding levels of the Rosenberg self-esteem scale. 


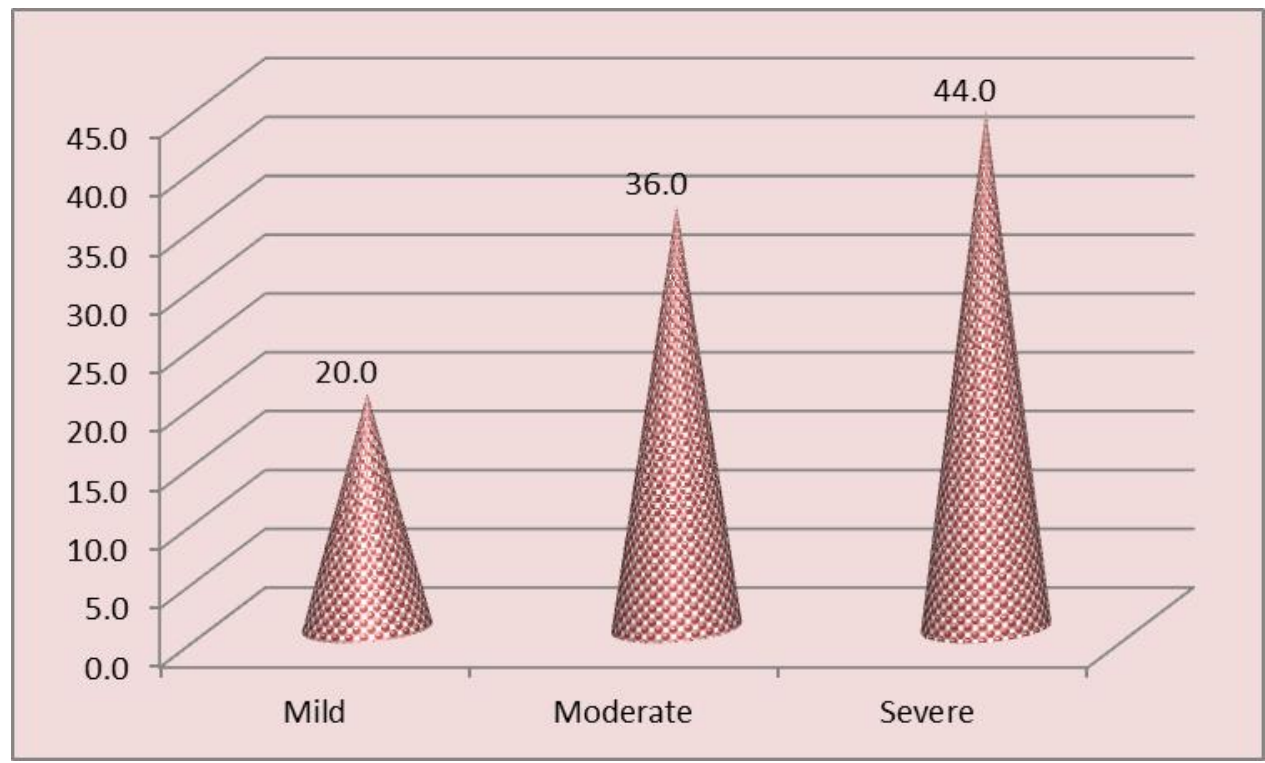

Figure (3) distribution of the studier subjects regarding levels of UCLA loneliness scale

Table (5): Correlation between Internalized Stigma (ISMI) and Self-Esteem among Studied Patients. $\mathrm{n}=100$

\begin{tabular}{|l|c|c|}
\hline \multirow{2}{*}{ Item } & \multicolumn{2}{|c|}{$\begin{array}{c}\text { Internalized stigma of mental illness inventory } \\
\text { (ISMI) }\end{array}$} \\
\cline { 2 - 3 } & $\mathbf{r}$ & p-value \\
\hline Rosenberg self-esteem scale & $-\mathbf{0 . 7 2}$ & $\mathbf{0 . 0 0 0}$ \\
\hline
\end{tabular}

Table (6): Correlation between Internalized Stigma of Mental Illness Inventory (ISMI) and UCLA Loneliness Scale among Studied Patients. $n=100$

\begin{tabular}{|l|c|c|}
\hline \multirow{2}{*}{ Item } & \multicolumn{2}{|c|}{ Internalized stigma of mental illness inventory } \\
\cline { 2 - 3 } & $\mathbf{r}$ & p-value \\
\hline UCLA loneliness scale & 0.81 & 0.000 \\
\hline
\end{tabular}

\section{Discussion}

Mental illnesses are medical conditions that disrupt a person's thinking, feeling, mood, ability to relate to others and daily functioning. Stigmatized individuals have been found to face a variety of social and emotional consequences, including social withdrawal, loss of productivity, lowered self-esteem, and increased levels of negative affect. Stigmatization is now recognized as perhaps the central issue facing all who are attempting to understand, prevent, and treat mental illness (Hinshaw\& Stier, 2008)\& (Rusch et al., 2014).

Regarding effect of internalized stigma on self-esteem, it was found that the stigma associated with mental illness harms the self-esteem of many people who have serious mental illnesses. An important consequence of reducing stigma would be to improve the selfesteem of people who have mental illnesses. In the present study, score on the stigma scale were highly negatively correlated with global self-esteem among the studied patients and this result answer our research question that selfstigma has a role on self-esteem among studied participants.

In the Egyptian study carried by Shalaby et al. (2014) to investigate" the role of internalized self-stigma on self-esteem and attitude toward seeking professional psychological help among psychiatric patients", their results indicated that $70 \%$ of studied patients have problematic 
internalized stigma. Also, their study stated that there is a negative relation between internalized self-stigma and self-esteem

Indeed, Corrigan et al. (2012) stated that the self-esteem of some people with serious psychiatric disorders may be hurt by internalizing stereotypes about mental illness and they also added that people with mental illness face a double-edged sword. Not only do they have to contend with serious, disruptive symptoms, they still have to deal with rampant stigma. Sadly, mental illness is still largely shrouded in stereotypes and misunderstanding.

In this point of the study, (Bolhari et al., 2002; Geoff, 2011) mentioned that, a progressive model of self-stigma yields four stages leading to diminished selfesteem and hope: being aware of associated stereotypes, agreeing with them, applying the stereotypes to one's self, and suffering lower self-esteem. They also reported that "People with a mental illness with elevated self-stigma report low self-esteem and low selfimage, and as a result they refrain from taking an active role in various areas of life, such as employment, housing and social life.

Regarding the effect of internalized stigma on loneliness, there was also highly positive statistical significant relation between experiences of internalized stigma and loneliness, this means that a more intense internalized stigma is associated with a higher sense of loneliness; this may be due to feelings of rejection and isolation changing the way people perceive and feel about themselves but also by affecting their perception of their social relations.

\section{Conclusion}

The results of the present study indicated that, internalized stigma played a detrimental role in undermining self- esteem and increasing loneliness among studied subjects.

\section{Recommendation}

Based on the current study findings, the following recommendations are suggested:

1- Develop anti-stigma campaigns dealing with mental illness.

2- It is important to establish and empower of user organizations for increasing the awareness of the problem of stigma in professional groups working with the mentally ill.

3- Psychological rehabilitative activities should be implemented in psychiatric institutions and rehabilitation centers.

4- Planning and implementation of public health awareness programs to raise the orientation toward the nature of psychiatric disorders to minimize the experience of stigma.

\section{References}

Bolhari, J., Nouri ,R., and Ramezani, A. (2002): In Z. Hussain Khan (Ed.), Quranic Verses on Mental Health for mental health workers and school counselors ;p. 22. Tehran: Office for Islamic

Corrigan, P., Morris, S., Michaels, P., Rafacz, J. and Rüsch, N. (2012): Challenging the public stigma of mental illness a metaanalysis of outcome studies. Psychiatry Serv; 63(10):963-973.

Cheon, B., and Chiao, J. (2012): Cultural Variation in Implicit Mental Illness Stigma. Journal of Cross-Cultural Psychology 43, 1058-1062.

Farrelly, S., Jeffery, D., and Rüsch , N. (2015): The link between mental health-related discrimination and suicidality: service user perspectives. Psychol Med 45:2013-2022 
Geoff, J. (2011): The Relationships of Public and Self-Stigma to Seeking Mental Health Services. Journal of Mental Health Counseling, , Vol. 33, No. 2

Guyll, M., Spoth, R. and Redmond, C. (2013): The effects of incentives and research requirements on participation rates for a community-based preventive intervention research study. Journal Of Primary Prevention 24, $25-41$.

Hinshaw, P., and Stier, A. (2008): Stigma as related to mental disorders. Annual Review of Clinical Psychology, 4, 367_393. doi:

/annurev.clinpsy.4.022007.141245

Hauge, S. and Kirkevold, M. (2012): Variations in older persons' descriptions of the burden of loneliness. Scandinavian Journal of Caring Sciences 26 (3), 553-560.

Oexle, N., Rüsch, N. and Viering, S. (2018): Self-stigma and suicidality: a longitudinal study. Eur Arch Psychiatry Clin Neurosci 267:359361

Ow, C and Lee, B. (2015): Relationships between perceived stigma, coping orientations, self-esteem, and quality of life in patients with schizophrenia Asia Pac J Public Health.. doi: 10.11 77/ 1010539512469246.

Rishter, E. and Jenifer, B. (2003): Internalized Stigma of Mental Illness: Psychometric Properties of a New Measure. Psychiatry Research 121(1):31-49.

Rüsch, N., Müller, M., Lay, B. and Corrigan, W. (2014): Emotional reactions to involuntary psychiatric hospitalization and stigma-related stress among people with mental illness. Eur Arch Psychiatry Clin Neurosci 264:35-43

Rosenberg, M. (1965): Society and the adolescent self-Image. Princeton, NJ:Princeton University Press. Journal of Personality and Social Psychology.89, 623-642.

Russel, L. (1980): Concurrent and discriminant validity evidence. Journal of Personality and Social Psychology. 39.472.480.

Shalaby, M., Sabra, A., and Mohamed, S. (2014): The Role Of Internalized Self Stigma On Self Esteem And Attitude Toward Seeking Professional Psychological Help Among Psychiatric Patients. International Journal of Current Research, Vol. 6, Issue, 11,pp.10162-10169, November, 2014.

Yanos, P., Lysaker, P. and Roe, D. (2014): Internalized stigma as a Barrier to Improvement Prevalence in vocational functioning among people with schizophrenia spectrum disorders. Psychiatry Research 178 (1), 211-213

Yen, F., Chen, C., Lee, Y. and Ko, C. (2015): Insight and correlates among outpatients with depressive disorders. Psychiatry Services 56, 599-601

Yuksel, C., Bingol, F. and Oflaz, F. (2013): Stigma: The cul-de-sac of the double bind' the perspective of Turkey; A phenomenological study. Journal of Psychiatric and Mental Health Nursing, 21, 667678. 